\title{
Bloodmeal sources and feeding behavior of anopheline mosquitoes in Bure district, northwestern Ethiopia
}

\author{
Tilahun Adugna ${ }^{1 *}$, Delensaw Yewhelew² and Emana Getu
}

\begin{abstract}
Background: Mosquito bloodmeal sources determine the feeding rates, adult survival, fecundity, hatching rates, and developmental times. Only the female Anopheles mosquito takes bloodmeals from humans, birds, mammals, and other vertebrates for egg development. Studies of the host preference patterns in blood-feeding anopheline mosquitoes are crucial to determine malaria vectors. However, the human blood index, foraging ratio, and host preference index of anopheline mosquitoes are not known so far in Bure district, Ethiopia.

Methods: The origins of bloodmeals from all freshly fed and a few half-gravid exophagic and endophagic females collected using Centers for Disease Control and Prevention light traps were identified as human and bovine using enzyme-linked immunosorbent assay. The human blood index, forage ratio, and host feeding index were calculated.

Results: A total of 617 specimens belonging to An. arabiensis $(n=209)$, An. funestus $(n=217)$, An. coustani $(n=123)$, An. squamosus $(n=54)$, and An. cinereus $(n=14)$ were only analyzed using blood ELISA. Five hundred seventy-five of the specimens were positive for blood antigens of the host bloods. All anopheline mosquitoes assayed for a bloodmeal source had mixed- rather than single-source bloodmeals. The FR for humans was slightly > 1.0 compared to bovines for all Anopheles species. HFI for each pair of vertebrate hosts revealed that humans were the slightly preferred bloodmeal source compared to bovines for all species (except An. squamosus), but there was no marked host selection.
\end{abstract}

Keywords: Anopheles arabiensis, An. coustani, Human blood index, Host preference index

\section{Introduction}

Malaria is transmitted by the blood feeding of infectious female Anopheles mosquitoes [1,2] and has a complex parasite life-cycle, which depends on both humans and mosquitoes [3, 4]. In Ethiopia, malaria is the leading health problem [5] because three-fourths $(75 \%)$ of the total area of the country is malarious and more than twothirds (approximately 68\%) of the total population lives below $2000 \mathrm{~m}$ altitude [5]. Amhara is one of the many regions in the country, and malaria remains a major

\footnotetext{
*Correspondence: tilahun46@yahoo.com; adugnawassie@gmail.com

${ }^{1}$ Debre Tabor University, P.O. Box 272, Debre Tabor, Ethiopia

Full list of author information is available at the end of the article
}

public health problem there. Bure is one of the approximately 15 districts in the region and carries $>13 \%$ of the malaria burden [6]. Across the country, the nature of malaria transmission is seasonal and unstable [7], varying with elevation, temperature, and rainfall $[8,9]$.

In Ethiopia, over 42 species of Anopheles have been identified [10, 11], but Anopheles arabiensis is the principal malaria vector while An. pharoensis, An. funestus, and $A n$. nili are secondary vectors [12, 13]. Therefore, understanding of the biology and behavior of Anopheles mosquitoes can help to understand how malaria is transmitted and can aid in designing appropriate control strategies [14]. Each species of Anopheles has its

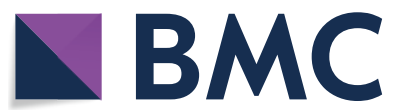

(c) The Author(s) 2021. This article is licensed under a Creative Commons Attribution 4.0 International License, which permits use, sharing, adaptation, distribution and reproduction in any medium or format, as long as you give appropriate credit to the original author(s) and the source, provide a link to the Creative Commons licence, and indicate if changes were made. The images or other third party material in this article are included in the article's Creative Commons licence, unless indicated otherwise in a credit line to the material. If material is not included in the article's Creative Commons licence and your intended use is not permitted by statutory regulation or exceeds the permitted use, you will need to obtain permission directly from the copyright holder. To view a copy of this licence, visit http://creativeco mmons.org/licenses/by/4.0/. The Creative Commons Public Domain Dedication waiver (http://creativecommons.org/publicdomain/ zero/1.0/) applies to the data made available in this article, unless otherwise stated in a credit line to the data. 
own blood-feeding pattern, host preference, biting, flight range, and host selection behavior $[15,16]$.

The blood-feeding behavior of malaria vectors is an important parameter in malaria epidemiology [3]. This behavior can influence vectorial potential [1], depending on the vertebrate host groups with which the mosquito makes contact, and influence the spatial distribution of a disease [17]. The most successful malaria vectors commonly feed on humans and secondarily on cattle and other domestic animals, depending on host availability [3]. Host choices and subsequent feeding success depend on host availability $[15,18]$ including host accessibility, density, host defense mechanisms, host size, proximity to mosquito habitats $[19,20]$, environmental factors, flight behavior, and feeding periodicity of the mosquitoes [21]. Interventions through long-lasting insecticide-treated nets (LLINs) and insecticide residual spraying (IRS) determine the successful feeding and oviposition nature of malaria mosquitoes [22].

Preference of anophelines to feed on humans can be estimated using the human blood index (HBI). HBI represents the proportion of bloodmeals derived from humans by mosquito vectors [23]. Study of the host-feeding pattern is an essential part of understanding the epidemiology of diseases transmitted by arthropods [24, 25]. Host preference studies have also been used to monitor the effectiveness of vector control programs by observing a reduction in blood-feeding behavior and have served as evidence of control failure [26-28].

Anophelines exhibit a wide range of host preferences, including humans, cattle, sheep, horses, pigs, dogs, cats, other mammals, birds, and reptiles [29-31]. Particularly animal-feeding vectors are known to suppress human bloodmeal sources and reduce the level of infection in the local vector population [32,33]. However, HBI results do not always reflect host preference [34, 35]. Therefore, several authors have proposed different indices to separate preferential versus opportunistic feeding patterns of mosquitoes [24, 36]. The forage ratio (FR) measures host selection patterns, i.e. quantifies vector selection of a particular vertebrate host rather than other available hosts [34]. It only shows the attributes of one host preference [23] and does not require a full host census [37]. The other parameter is the feeding index (FI), which compares the observed proportion of blood feeds from one host to another host divided by the expected comparative proportion of feeds on the two hosts [17, 24].

Generally, the knowledge of the HBI, blood-feeding preferences, and pattern of a mosquito species provides insight into its vector potential $[17,38]$ and the epidemiology of disease transmission $[24,25,29,39]$ and allows designing and implementing efficient strategies for vector control $[23,29,30]$. For our study, the HBI, FR, and host preference index (HFI) of anopheline mosquitoes have not been known so far, so we aimed to determine the abdominal status, HBI, FR, and HFI of anopheline mosquitoes in Bure district, northwest Ethiopia.

\section{Materials and methods Study area}

A longitudinal study was conducted in Bure district, northwestern Ethiopia, from July 2015 to June 2016. Geographically, Bure district is situated at an altitude ranging from 700 (Blue Nile gorge) to $2350 \mathrm{~m}$ above sea level (Fig. 1). Socioeconomically, the majority (85\%) of the population is farmers who grow maize, teff (Eragrostis teff), pepper, potatoes, wheat, and millet, followed by beans and peas, sunflowers, niger, spices, vegetables, and others. The rest of the population includes merchants (6.8\%) and others (non-governmental organizations, civil servants) (8.2\%). Animals such as cattle, sheep, hens, mules, and donkeys are reared by most farmers. The proportions of the animals reared in the study district are described in Table 2. In addition, there are both modern and traditional beekeepers. Most of the population in the district lives in houses made of mud with corrugated iron roofs. The mud houses are partly smooth and partly rough. Some of them are painted. The doors and windows of the houses do not have mosquito screening. In each farmer's compound, there is a separate kitchen and latrine house. The distance between farmers' houses is $10-15 \mathrm{~m}$. Both humans and animals live inside the same house.

Most of Bure district has a subtropical zone (WoinaDega) climate with annual mean minimum and maximum temperature of $9.9{ }^{\circ} \mathrm{C}$ and $29.2{ }^{\circ} \mathrm{C}$, respectively, and $2000 \mathrm{~mm}$ mean annual rainfall ranging being 1350 $2500 \mathrm{~mm}$. The major rainy season of the district is from July to September, and a small amount falls from May to June and from October to December. The other months (January-April) are dry seasons [40].

The study was conducted in three rural villages, Bukta, Workmidr, and Shnebekuma, from July 2015-June 2016. The detailed description of the three villages is provided elsewhere [41]. These villages are malarious. Bed nets have been distributed to the three villages once every 3 years before malaria infestation begins, in the first week of September. Moreover, anti-malaria chemical spraying (IRS) (Deltamethrin, K-Othrine Flow) has been administered in the three villages according to the national spraying operation guidelines [12].

\section{Adult mosquito collection, identification, and processing Mosquito collection}

Anopheles mosquitoes were collected each month from July 2015-June 2016 using Centers for Disease Control 


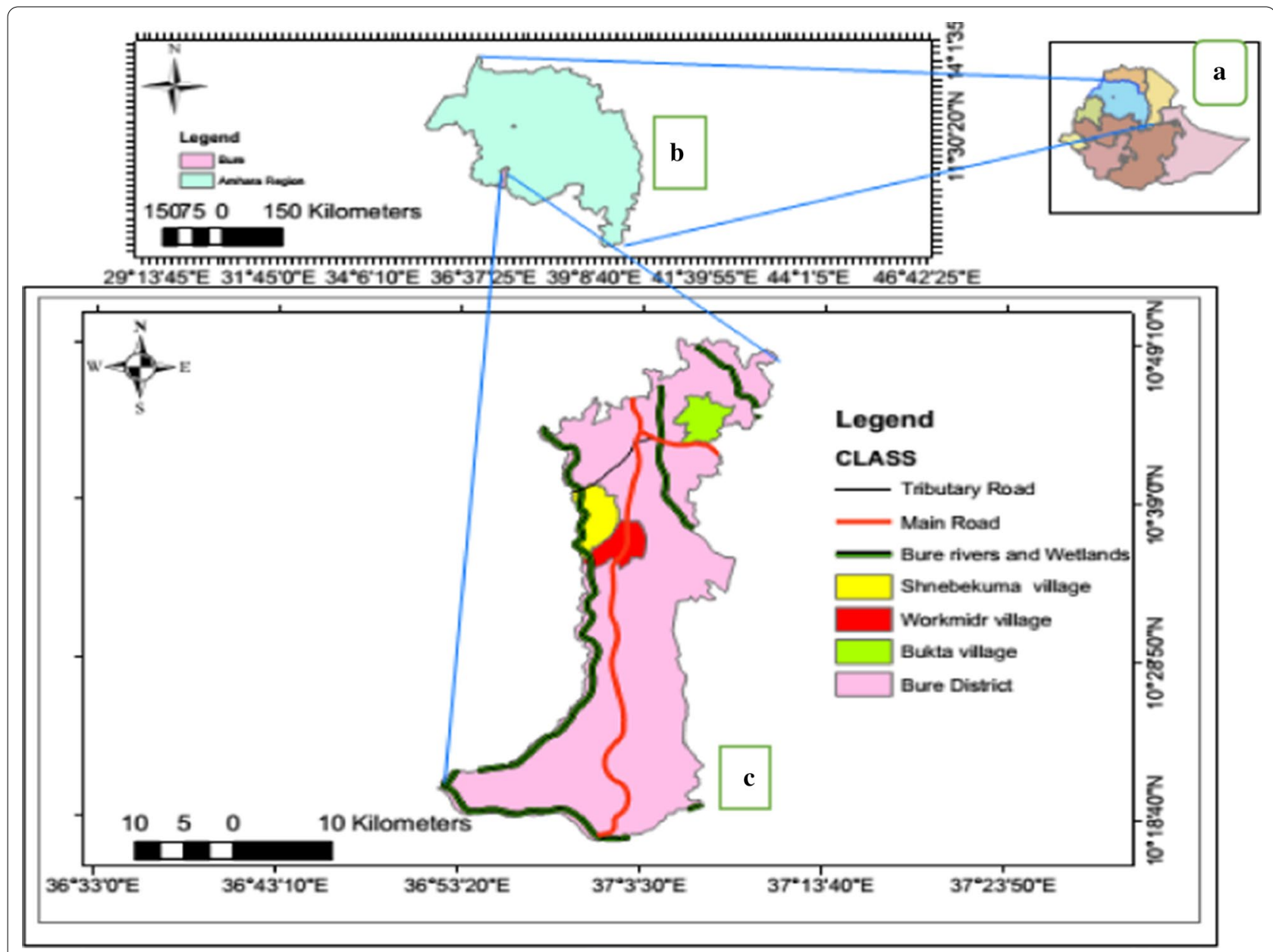

Fig. 1 Map of the study area. a Ethiopia, b Amhara region, and c Bure district

and Prevention light trap catches (LTCs), pyrethrum spray catches (PSCs), and artificial pit shelters (APSs). In each village, nine houses for LTCs and ten houses for PSCs were randomly selected, distributed near the breeding sites, in the middle and on the periphery of the village. Similarly, nine LTCs were prepared to collect outdoor host-seeking mosquitoes in each village. In addition, six APSs were prepared in three villages to collect outdoor resting mosquitoes; each village had two.

Indoor host-seeking Anopheles mosquitoes were collected from 6:00 p.m. (sunset) to 6:00 a.m. (sunrise) using LTCs (Model 512; J. W. Hock Co., Atlanta, GA, USA) once per month per house for 1 year $[42,43]$. Likewise, the outdoor host-seeking mosquitoes were collected by LTCs from 06:00 p.m. to 06:00 a.m. once per month. Indoor-resting mosquitoes were collected in the mornings from 6:00 a.m. to 8:30 a.m. using PSCs for 1 consecutive year. Collection was carried out using white floor sheets, hand lenses, baygon aerosol (Tetramethrin: 0.4\% and Permethrin: 0.4\%; SC. Johnson \& Sons Inc., USA), small Petri dishes, paper cups with net covers, forceps, cotton wool, and a torch [44].

Additionally, outdoor-resting mosquitoes were collected in the morning from 6:30 a.m. to 7:30 a.m. using APSs by handheld mouth aspirator. APSs were constructed under the shade of various dense shrub trees 10-15 $\mathrm{m}$ away from the residential villages. Before collection began, the mouth of each pit shelter was covered with insecticide-untreated white net to prevent mosquitoes from escaping and for visibility purposes. Resting mosquitoes were collected for about 10-20 min in each pit [45]. The number of human occupants and other potential vertebrate hosts in each surveyed house during the previous night was recorded (Table 2). Moreover, the condition of each surveyed house was recorded, including the type of house, type of walls, number of longlasting insecticide-treated nets (LLINs) used, and spray status.

Collection of mosquitoes was carried out after obtaining ethical approval from the ethics review 
committee of Addis Ababa University (reference no. CNSDO/382/07/15), Amhara Health Regional Bureau (permission reference no. $\mathrm{H} / \mathrm{M} / \mathrm{TS} / 1 / 350 / 07)$, and the Head of the Bure District Health Office (permission reference no. $\mathrm{BH} / 3 / 519 \mathrm{~L} / 2)$. Moreover, informed consent was obtained from the heads of the selected households.

\section{Anopheles mosquito species identification}

Mosquitoes collected by LTCs, PSCs, and APSs were identified morphologically at the genus level using taxonomic keys [46, 47]. In addition, morphologically identified and separately stored An. gambiae specimens were identified by species-specific PCR [48] at the Molecular Biology Laboratory of Tropical and Infectious Diseases Research Center, Jima University. Then, DNA was extracted from individual preserved An. gambiae complex species based on DNeasy Blood and Tissue Kits [49]. DNA amplification was then carried out followed by gel electrophoresis [48]. Finally, agarose gel was placed on the UVP. Those mosquitoes that remained unamplified were tested three times independently.

\section{Survey of vertebrate hosts}

Human and domestic animal (hens and mammals) census reports were obtained by interviewing the heads of households during house-to-house visits in the district. The number of humans and domestic vertebrates in neighboring houses was not counted. Potential blood hosts for Anopheles mosquitoes from PSCs were not included because of the presence of fewer engorged Anopheles.

\section{Determination of abdominal status of Anopheles mosquitoes}

The abdominal conditions of Anopheles were determined based on blood digestion and ovarian development using standard keys as unfed, freshly fed, half-gravid, and gravid [50]. Finally, freshly fed and half-gravid anophelines were taken to Jima University for bloodmeal ELISA (enzyme-linked immunosorbent assay) tests.

\section{Identification of the bloodmeal sources of Anopheles mosquitoes}

The origins of bloodmeals of all freshly fed and a few half-gravid female Anopheles mosquitoes (An. arabiensis, An. funestus, An. coustani, An. squamosus, and An. cinereus) collected using LTCs were identified as human and bovine using ELISA [51]. Each mosquito abdomen was ground with $100 \mu$ l of phosphate-buffered saline (PBS) using an electrical pestle. The pestle was rinsed with $100 \mu \mathrm{l}$ PBS to make a total of $200 \mu \mathrm{l}$ final volume, and $100 \mu \mathrm{l}$ homogenate was added to 96-well ELISA plates. Similarly, $100 \mu \mathrm{l}$ animal sera (1/100 in PBS) and
$100 \mu \mathrm{l}$ unfed female adult Anopheles mosquitoes of each species (from a laboratory colony) were added to 96-well ELISA plates as a positive and negative control, respectively. Moreover, $100 \mu \mathrm{l}$ PBS was used alone as a negative control. Then, the plates were covered and incubated at room temperature for $2 \mathrm{~h}$. After incubation, the well contents were discarded, and they were tapped upside-down five times on tissue paper and washed three times with $200 \mu \mathrm{l}$ PBS-Tween-20 using ELISA washer. Then, $50 \mu \mathrm{l}$ human peroxidase conjugate (lot no. 023M4782; batch no. 023M4782; product no. A0170) was added; plates were covered and incubated for $1 \mathrm{~h}$ at room temperature. Plates were washed with ELISA washer three times with $200 \mu \mathrm{l}$ PBS-Tween-20, and $100 \mu \mathrm{l}$ of ABTS was added to each well and incubated for $30 \mathrm{~min}$ for human blood detection.

To bovine blood sources, $50 \mu$ l bovine phosphatase conjugate (lot no. 062M4761V/Sigma-Aldrich.com) was added and then covered and incubated for $1 \mathrm{~h}$ at room temperature. The wells were washed three times with $200 \mu \mathrm{l}$ PBS-Tween-20 with ELISA washer, and $100 \mu \mathrm{l}$ pNPP (catalog no. 0421-01; lot no. H4014-VG96) substrate was added to each plate and incubated for $1 \mathrm{~h}$. Finally, positive samples, including positive control, were changed to blue-green color for human blood (peroxidase) and dark yellow reactions (phosphatase) for bovine blood (detected visually). Immediately, using the ELISA reader, the value of each plate was determined at $405 \mathrm{~nm}$ wavelength. Samples were considered positive if absorbance values exceeded two times the mean of three negative controls, unfed mosquitoes/PBS-blank solution.

\section{Data analysis}

Data were entered and cleaned using Microsoft Excel 2007 and analyzed using the SPSS software package, version 20.0 (SPSS, Chicago, IL, USA). Before applying mean comparison, normality of bloodmeal sources (host types), $\mathrm{HBI}$, and BBI data were checked, and data were log transformed [log $10(x+1)]$. The HBI and bovine blood index (BBI) were calculated as the proportion of mosquitoes that fed on human and bovine bloodmeals out of the total bloodmeals determined/tested [23]. Mixed (human + bovine) bloodmeals were added to the number of a human and bovine bloodmeals when calculating the overall HBI and BBI. The presence of significant differences between $\mathrm{HBI}$ and BBI and indoor and outdoor HBI/ BBI was checked by independent $t$-test $(p<0.05)$. Variation among bloodmeal sources (host types) for Anopheles mosquitoes was separated by one-way ANOVA. The Tukey HSD test was run for mean separation variation (in ANOVA) (HSD) $(p<0.05)$. Statistical test significance was considered at $p<0.05$ during the analysis. 
Foraging ratios (FRs) were determined to obtain the proportion of bloodmeals taken only from humans and cattle. FRs were calculated as the percent of female Anopheles mosquitoes (five species as described in the Results section) containing blood of a particular host divided by the percent of the total available host population represented by the particular host [36] as follows:

$$
\mathrm{FR}=(\mathrm{NAE} / \mathrm{NTE}) /(\mathrm{NAP} / \mathrm{NTP})
$$

where $\mathrm{FR}=$ the foraging ratio of Anopheles species, $\mathrm{NAE}=$ number of engorged female mosquitoes containing blood from host-1, NTE = total number of engorged females, NAP $=$ number of type 1 hosts in the collection area, and NTP = total number of hosts of all types in the collection area.

A foraging ratio of 1 indicated neither a selective bias nor avoidance of a particular host animal (opportunistic $=$ equally feeding); FRs significantly $>1$ indicated a selective bias, and values $<1$ indicated avoidance of a host in favor of other available hosts [24, 36]. However, in our study, the percentage of FRs was only calculated for humans and cattle, and comparison was made between the two hosts. The host preference indices (HFI) is defined as the observed proportion of feeding on one host compared to another divided by the expected comparative proportion of feeds on these two hosts [17, 24]; the formula is as follows:

$$
\mathrm{HFI}=(N x / N y) /(A x / A y)
$$

where ' $N x$ ' and ' $N y$ ' are the mean numbers of bloodmeals taken from hosts ' $x$ ' and ' $y$ ' per study site, respectively, and ' $A x$ ' and ' $A y$ ' are the mean numbers of hosts ' $x$ ' and ' $y$ ' per study site, respectively. An index of 1 indicated equal feeding on the two hosts. HFI $>1$ indicated that host ' $x$ ' was preferentially fed upon, whereas a value $<1$ indicated that host ' $y$ ' was preferentially fed upon [17]. HFIs were calculated for each pair of hosts (humans: cattle) [24].

\section{Results}

Abdominal status of female Anopheles mosquitoes

The overall abdominal status of each adult female Anopheles mosquito is presented in Table 1 and Fig. 2. Of 4703 Anopheles mosquitoes collected, a higher proportion of mosquitoes were unfed (69.7\%), followed by fed (24.5\%), gravid (3.9\%), and half-gravid (1.9\%).

Overall, 56.0\% $(n=646 / 1153)$ fed Anopheline mosquitoes were from indoor and 44.0\% $(n=507 / 1153)$ from outdoor collections. The proportion of half-gravid (HG) mosquitoes collected outdoors $(n=50,56.2 \%)$ was greater than that of HG mosquitoes collected indoors $(n=39,43.8 \%)$. Collection method comparison indicated that $>99.6 \%$ of unfed (UF), fed (F), HG, and gravid (G) were collected by LTCs while the remaining catches were by PSCs. However, APSs was not fully productive (Table 1). Because of the unsuccessful catches by PSCs and APS, the degrees of exophily and endophily behavior were not determined.

\section{Compositions and abundances of potential vertebrate hosts for Anopheles mosquitoes}

A total of 3803 hosts were recorded from 324 surveyed houses in three villages. Of these, hosts from Bukta accounted for $39.2 \%$, Shnebekuma 33.0\%, and Workmidr $27.8 \%$. Hosts included: bovines (40.0\%), humans (37.7\%), sheep (16.0\%), donkeys $(0.8 \%)$, mules $(0.7 \%)$, chickens (4.0\%), and dogs $(0.7 \%)$. Of these, a higher proportion of human and cattle hosts was recorded in the study area $\left(\mathrm{F}_{6,77}=160.863 ; p=0.001\right)$ (Table 2).

\section{Distribution of bloodmeals across villages}

As indicated in Table 3, 609 (collected by LTs) Anopheles mosquitoes were assayed for bloodmeal source analysis using ELISA. Most of them had fed ( $n=575$, 94.4\%); however, the distribution was not equal, and a large proportion was from Shnebekuma (76.5\%). In the study area, both humans and animals were living in the same

Table 1 Abdominal status of female Anopheles mosquitoes by place and method of collection in Bure district, Ethiopia, from July 2015

\begin{tabular}{|c|c|c|c|c|c|c|c|}
\hline \multirow{3}{*}{$\begin{array}{l}\text { Blood digestion } \\
\text { stage }\end{array}$} & \multicolumn{3}{|l|}{ Place of collection } & \multicolumn{4}{|c|}{$\%$ Abdominal status by method of collection } \\
\hline & \multirow{2}{*}{$\begin{array}{l}\text { Indoor } \\
\text { (LTs and PSCS), n (\%) }\end{array}$} & \multirow{2}{*}{$\begin{array}{l}\text { Outdoor } \\
\text { (LTs), n (\%) }\end{array}$} & \multirow[t]{2}{*}{ Total (\%) } & & & & \\
\hline & & & & LTs, $n(\%)$ & PSCs, $n(\%)$ & APTs, $n(\%)$ & Total (\%) \\
\hline UF & $1023(31.2)$ & $2253(68.8)$ & $3276(69.7)$ & $3267(99.7)$ & $9(0.3)$ & 0 & $3276(69.7)$ \\
\hline $\mathrm{F}$ & $646(56.0)$ & $507(44.0)$ & $1153(24.5)$ & 1145 (99.3) & $8(0.7)$ & 0 & $1153(24.5)$ \\
\hline HG & $39(43.8)$ & $50(56.2)$ & $89(1.9)$ & $89(100.0)$ & 0 & 0 & $89(1.9)$ \\
\hline G & $89(48.1)$ & $96(51.9)$ & $185(3.9)$ & $183(98.9)$ & $2(0.1)$ & 0 & $185(3.9)$ \\
\hline Total & $1797(38.2)$ & $2906(61.8)$ & $4703(100)$ & $4684(99.6)$ & $19(0.4)$ & 0 & $4703(100)$ \\
\hline
\end{tabular}
to June 2016

Unfed (UF), fed (F), half-gravid (HG), and gravid (G) 


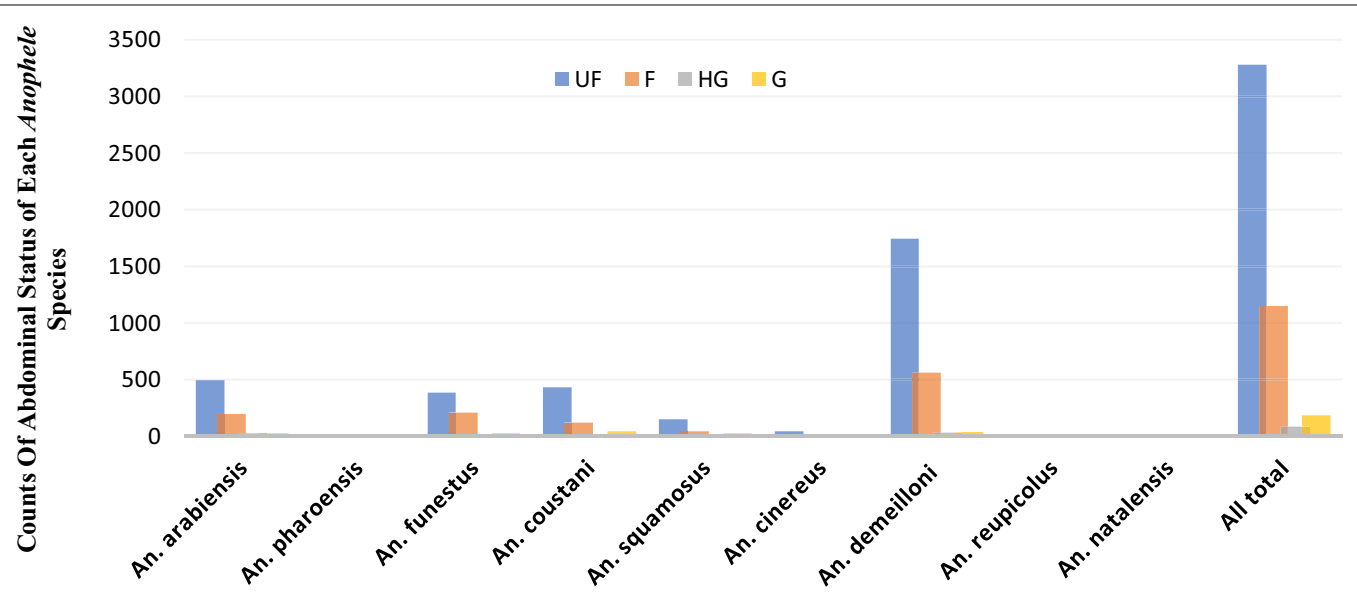

Feeding Statuses of Anopheles Species:

Fig. 2 Abdominal statuses of Anopheles mosquito species in Bure district, Ethiopia. UF, unfed; F, fed; HG, half gravid; G, gravid

Table 2 Mean difference between hosts

\begin{tabular}{ll}
\hline Identified hosts & $(\mathrm{M} \pm \mathrm{SE})$ \\
\hline Humans & $4.419 \pm 0.07^{\mathrm{a}}$ \\
Bovines (cattle) & $4.681 \pm 0.100^{\mathrm{a}}$ \\
Sheep & $1.881 \pm 0.093^{\mathrm{b}}$ \\
Donkeys & $0.166 \pm 0.045^{\mathrm{b}}$ \\
Mules & $0.180 \pm 0.046^{\mathrm{b}}$ \\
Hens & $1.417 \pm 0.252^{\mathrm{b}}$ \\
Dogs & $0.2658 \pm 0.05973^{\mathrm{b}}$ \\
\hline
\end{tabular}

houses. Of these, most mosquitoes had a mixed bloodmeal source (human and bovine) $(88.8 \%, n=541)$. The proportion of mixed blood meals was greater than that of single bloodmeals (either human or bovine) across the three villages. However, a higher proportion of mixed blood $(74.4 \%, n=419 / 541)$ was recorded in Shnebekuma.

\section{Bloodmeal indices of Anopheles mosquitoes}

Table 4 shows the bloodmeal origins and HBI of Anopheles mosquitoes by site and collection method. Overall,
617 (LTs and PSCs) Anopheles mosquitoes (fed and HG) belonging to five species (An. arabiensis, An. funestus, An. coustani, An. squamosus, and An. cinereus) were tested by ELISA. Of these, $94.2 \%(n=581)$ were positive for host blood antigen and the remaining 5.8\% $(n=36)$ were unidentified. From 581 positive samples (LTs and PSCs), the largest proportion $(99.0 \%, n=575)$ was from LTCs and the smallest proportion $(1.0 \%, n=6)$ from PSCs. Of 575 positive samples (LTs), the majority (5p7\%) was from indoor collection.

Of 208 tested An. arabiensis, only $94.7 \%$ were positive. Of these positive bloodmeals, 91.8\% were mixed bloodmeal (LTs-in and out) and 3.0\% only of bovine bloodmeal origin. No single An. arabiensis specimen had blood from human only. However, the indoor and outdoor HBI $(t=1.587 ; d f=22 ; p=0.127)$, BBI $(t=1.406 ; d f=22$; $p=0.173)$, and overall HBI and BBI of An. arabiensis did not show any statistically significant difference between them $(t=-0.05 ; d f=22 ; p=0.961)$.

The result of this study revealed that from 213 tested An. funestus specimens, only $95.8 \%$ were positive for bloodmeal ELISA. Of the total positive specimens, 91.5\% had mixed bloodmeals (LTs, inside and outside), and the

Table 3 Distribution of bloodmeal sources of Anopheles mosquitoes in the three villages using LTs in Bure, Ethiopia, from July 2015 to June 2016

\begin{tabular}{|c|c|c|c|c|c|}
\hline Villages & $\begin{array}{l}\text { Total numbers of tested } \\
\text { mosquitoes (\%) }\end{array}$ & $\begin{array}{l}\text { Total tested positive } \\
\text { mosquitoes (\%) }\end{array}$ & $\begin{array}{l}\text { Only human blood } \\
\text { positive (\%) }\end{array}$ & $\begin{array}{l}\text { Only hovine blood } \\
\text { positive (\%) }\end{array}$ & Mixed \\
\hline Bukta & $88(14.4)$ & 79 (13.7) & $2(100)$ & $7(21.9)$ & 70 (12.9) \\
\hline Workmidr & $58(9.5)$ & $56(9.7)$ & 0 & $4(12.5)$ & $52(9.6)$ \\
\hline Shnebekuma & $463(76.1)$ & $440(76.5)$ & 0 & 21 (65.6) & 419 (77.4) \\
\hline All total & 609 (100\%) & $575(100)$ & $2(100)$ & $32(100)$ & $541(100)$ \\
\hline
\end{tabular}




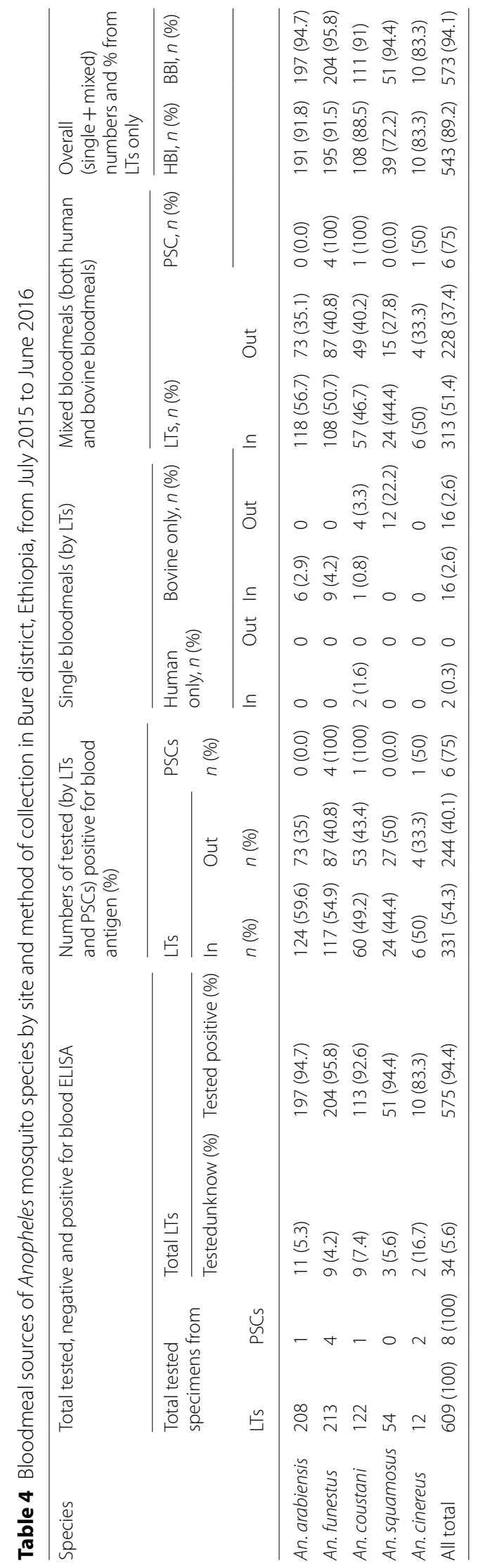


remaining $4.2 \%$ had only bovine. From mixed bloodmeals, 54.9\% were from indoor and 40.8\% from outdoor collection. However, a single bovine bloodmeal was found from indoor collection. The overall (single plus mixed) HBI of An. funestus was 91.5\%, which was slightly less than that of the overall BBI $(95.8 \%)$. However, the indoor and outdoor HBI $(t=1.322 ; d f=22 ; p=0.2)$, BBI $(t=1.355 ; d f=22 ; p=0.189)$ and overall HBI and BBI of An. funestus did not show any statistically significant difference between them $(t=-0.168 ; d f=22 ; p=868)$.

A total of 122 specimens of An. coustani were tested for blood ELISA. Most (92.6\%) were positive for blood feeding, and the rest had bovine (4.1\%) and human blood meals only (1.6\%). Of these, the overall mixed bloodmeal (LTs-in and out) was $86.9 \%$. For all positive samples, $49.2 \%$ were from indoor collection and $43.4 \%$ from outdoor collection. An. coustani was the only species that had only human bloodmeals. However, the indoor and outdoor HBI $(t=0.546 ; d f=22 ; p=0.591)$ and BBI $(t=0.662 ; d f=22 ; p=0.515)$ as well as overall HBI and $\mathrm{BBI}$ of An. arabiensis did not show any statistically significant differences between them $(t=-0.043 ; d f=22$; $p=0.966)$. Similar to this species, both An. squamosus and $A n$. cinereus did not show any statistically significant difference between the indoor and outdoor HBI and BBI and overall HBI and BBI $(p>0.05)$.

\section{Foraging ratio and host feeding/preference index of Anopheles mosquitoes}

The foraging ratio values and feeding preference index of Anopheles mosquitoes are presented in Table 5. Humans and cattle were the most common vertebrate hosts in the study area (Table 2). The FR for humans was slightly $>1.0$ for all Anopheles species. Similarly, the FR for cattle was slightly $>1.0$ for all Anopheles species. Calculation of the HFI for each pair of vertebrate hosts revealed that humans were the preferred bloodmeal source for bovines for all species (except An. squamosus), but there was no marked host selection (Table 5).

\section{Discussion}

In this study, $>95 \%$ of Anopheline mosquitoes were collected by LTCs. This is identical to other findings in which more malaria vectors were trapped while host seeking than resting [52-56]. Of the 4703 collected mosquitoes, most (69.7\%) were unfed. Consistent with our study, Fornadel et al. [57] in Zambia, Bashar et al. [58] in Bangladesh, and Getachew et al. [56] in Ethiopia collected mostly unfed Anopheles mosquitoes using LTCs. These unfed mosquitoes are stimulated and attracted by the light generated by incandescent bulbs from light traps $[58,59]$. As a result, mosquitoes were caught while searching for their bloodmeals before they took blood. However, contrary to this study, Animut et al. [60] collected more freshly fed than unfed Anophelines species using light traps in Ethiopia. The catches of more freshly fed mosquitoes using light traps could be due to the recapturing of mosquitoes after repeated feeding behavior [61].

This study revealed that the majority of the bloodmeal sources of Anopheles mosquitoes were mixed bloodmeal (both human and bovine) $(88.8 \%, n=541)$, which was extremely large compared with single bloodmeal sources. Compared with villages, most blood-feeding mosquitoes were from Shnebekuma village $(77.4 \%, n=419)$. This implies that this village needs more attention than the rest.

The present study showed that no single An. arabiensis specimen had a human bloodmeal origin. This is inconsistent with the reports of Massebo et al. [62]

Table 5 Foraging ratio (FR) and host preference/feeding index (HFI) of Anopheles mosquitoes in Bure, Ethiopia, from July 2015 to June 2016

\begin{tabular}{|c|c|c|c|c|c|c|c|}
\hline \multirow[t]{2}{*}{ Hosts } & \multirow{2}{*}{$\begin{array}{l}\text { Vertebrate } \\
\text { Host, } n(\%)\end{array}$} & \multirow[t]{2}{*}{ Mosquito species } & \multirow[t]{2}{*}{$\mathrm{HBI}$} & \multirow[t]{2}{*}{$\mathrm{BBI}$} & \multicolumn{2}{|c|}{ Total FR } & \multirow{2}{*}{$\begin{array}{l}\mathrm{HPI} \\
\text { human: } \\
\text { bovine }\end{array}$} \\
\hline & & & & & $\mathrm{HBI}$ & $\mathrm{BBI}$ & \\
\hline Human & 1435 (48.6) & An. arabiensis & 91.8 & - & 1.88 & - & 1.03 \\
\hline Cattle & $1520(51.4)$ & & - & 94.7 & - & 1.84 & \\
\hline Human & 1435 (48.6) & An. funestus & 91.5 & - & 1.88 & - & 1.01 \\
\hline Cattle & $1520(51.4)$ & & - & 95.8 & - & 1.86 & \\
\hline Human & 1435 (48.6) & An. coustani & 88.5 & - & 1.82 & - & 1.03 \\
\hline Cattle & $1520(51.4)$ & & - & 91 & - & 1.77 & \\
\hline Human & 1435 (48.6) & An. squamosus & 72.2 & & 1.49 & - & 0.81 \\
\hline Cattle & $1520(51.4)$ & & - & 94.4 & - & 1.84 & \\
\hline Human & 1435 (48.6) & An. cinereus & 83.3 & - & 1.71 & - & 1.06 \\
\hline Cattle & $1520(51.4)$ & & - & 83.3 & - & 1.62 & \\
\hline
\end{tabular}


(8.0\%), Animut et al. [60] (33.7\%), Yewhalaw et al. [63] (6\%), Getachew et al. [56] (50.7\%), and Ngom et al. [64] (40.1\%) in Ethiopia and Senegal. On the other hand, the presence of single bovine blood origins of An. arabiensis (2.9\%) was minimal compared to the reports of Massebo et al. [64], Animut et al. [60], Yewhalaw et al. [63], and Getachew et al. [56], which found 7.1\%, 38.2\%, 23.5\%, and 20.9\% bovine bloodmeals in Ethiopia, respectively (using LTs). This is probably due to the presence of high human populations as well as cattle for bloodmeal sources, diverting more $A n$. arabiensis to feed on both humans and cattle.

In the present study, the majority of An. arabiensis had mixed bloodmeals, which was higher compared to other studies $[56,60,63,64]$ that reported $65 \%, 13.2 \%, 1.6 \%$, and $4.4 \%$ in various parts of south and southwest Ethiopia, respectively. The highest proportion of mixed feeding implies that the sites are mixed dwellings (humans and cattle) $[29,65]$. The practice of having humans, cattle, hens, donkeys, mules, etc., in the same house (one house) was confirmed during this survey (personal observation), which contributes to having higher rates of mixed feeding because of the alternative hosts. Moreover, this is also probably associated with the very high incidence of disturbances [34] or climatic factors [58, 65]. Generally, in this study the proportion of mixed bloodmeals was higher than that of single feeding, implying that $A n$. arabiensis has plasticity in feeding behavior in the area. Other studies also strengthen this finding [66-69].

The overall HBI and BBI and indoor and outdoor HBI and BBI of An. arabiensis did not show any statistically significant differences between them, which indicates opportunistic feeding behavior in the area. Similar feeding preferences are reported from southern Ethiopia where people and livestock either share the same houses or where cattle are kept separate but close to houses during the night $[60,70]$.

This study demonstrated that most An. funestus had mixed bloodmeals (humans and cattle) but no single human bloodmeal was detected, similar to An. arabiensis. The absence of a single human bloodmeal source is in agreement with the findings Massebo et al. [64] but contradicts other studies $[71,72]$ that reported an extremely high single HBI for An. funestus in Kenya (90.8\%, 99.5\%) and Cameroon (98\%), respectively. Therefore, our result indicated that An. funestus changes its bloodmeal sources from only humans $[67,73]$ to both cattle and humans. Various reports have indicated that An. funestus now feeds on the blood of humans, goats, calves, chickens, cows, dogs, goats, and equines [66-69], depending on the availability of host types.

The overall (single plus mixed) HBI and BBI and indoor and outdoor HBI and BBI of An. funestus did not show any statistically significant differences among them, indicating its opportunistic feeding behavior in the area. However, the overall (single plus mixed) HBI (91.5\%) and BBI (95.8\%) of An. funestus were higher than other findings from Kenya $(\mathrm{HBI}=25.2 \% ; \mathrm{BBI}=57.7 \%)[68]$ and Ethiopia $(\mathrm{HBI}=86.0 \%$; $\mathrm{BBI}=14.3 \%)$ [74]. These equal proportions of bloodmeal sources in our study were due to the practice of mixed dwelling activities in the three villages. In Ethiopia, An. arabiensis and An. funestus are well-known malaria vectors [12, 13]. In Bure district, these species were found together with Plasmodium species [76]. Therefore, the role of mixed dwellings and combination zooprophylaxis should be appreciated to discourage the roles of these species in malaria transmission.

The blood ELISA result of An. coustani indicated that the majority $(92.6 \%)$ of this species had mixed bloodmeals, and the rest had only bovine (4.1\%) and human bloodmeals (1.6\%). Though proportionally different, Muriu et al. [68] reported $71.4 \%$ and $5.4 \%$ of An. coustani feeding on humans and bovines blood alone in Kenya, respectively. In southwest Ethiopia, Getachew et al. [56]. also reported that An. coustani had 3.3\% (2/59) human and $92.8 \%(64 / 69)$ bovine bloodmeals alone. In our study, An. coustani was found with human bloodmeals, which is corroborated by Getachew et al. [56]. On the contrary, Yewhalaw et al. [63] did not detect any An. coustani with human blood in southwest Ethiopia. Although this species still was not confirmed as a malaria vector in Ethiopia, many studies in Ethiopia [63, 75, 76], Cameroon [77], and Kenya [78, 79] have reported An. coustani with malaria parasites (Plasmodium spp.). These results suggest that An. coustani is responsible for malaria transmission in Bure district.

Moreover, the FRs for humans were $>1.0$ for all of the anopheline species, except An. squamosus. Based on the HFIs for each pair of vertebrate hosts, humans were relatively the preferred blood source for all tested species, except for An. squamosus. The limitation of this study is that the other bloodmeal sources of Anopheles mosquitoes (blood ELISA), such as sheep, donkeys, mules, hens, and dogs, were not determined although they were recorded in the district. Therefore, HFI could not be calculated for the aforementioned vertebrate hosts.

\section{Conclusions}

This animal census survey indicated that humans, bovines, sheep, donkeys, mules, hens, and dogs were the common vertebrate hosts in the study area; however, the proportions of humans and bovines were significantly high. Therefore, Anopheles mosquitoes have many alternative bloodmeal sources. Houses were traditional (made of mud) and served for cooking, 
sleeping, and tethering of livestock, resulting in higher indoor temperatures. Hence, this microclimate attracts more mosquitoes and provides more access to bloodmeal sources, and a relatively high proportion of indoor feeding mosquitoes were recorded.

All the anopheline mosquitoes assayed for blood ELISA indicated the presence of a high proportion of mixed bloodmeals (humans and cattle), which is very important compared to single human meals because mixed feeding tends to diminish the density of gametocytes in the mosquito stomach, thereby reducing the chance of fertilization of female gametes and reducing the chances of malaria vector infection $[34,58,64,68$, 80]. Moreover, among assayed anopheline mosquitoes, only An. coustani had solely human blood, implying that his species may be linked with malaria transmission. Therefore, proper investigation is required to gain certainty about its role as a malaria vector. Further confirmation is needed on whether the existing intervention activity against An. coustani is fully effective or not. Combination zooprophylaxis should be reinforced as a means of vector control because the study sites are mixed dwellings.

\begin{abstract}
Abbreviations
MoH: Ethiopian Ministry of Health; PMI: President's Malaria Initiative; LLINs: Long-lasting insecticide-treated nets; IRS: Insecticide residual spraying; $\mathrm{HBI}$ : Human blood index; FR: Forage ratio; Fl: Feeding index; HFI: Host preference index; WHO: World Health Organization; ELISA: Enzyme-linked immunosorbent assay; CDC: Centers for Disease Control and Prevention; LTCs: Light trap catches; BBI: Bovine blood index; HG: Half gravid; PSCs: Pyrethrum spray catches; APSs: Artificial pit shelters; UF: Unfed; F: Fed; G: Gravid.
\end{abstract}

\section{Acknowledgements}

We thank the communities of Bukta, Shnebekuma, and Workmidr, Bure district, for their cooperation with collecting adult mosquitoes during our survey. Our deepest gratitude goes to Malaria Consortium, Ethiopia, for providing CDC LTs and internet services. We acknowledge to Dr. Habte Tekie for his engagement and provision of CDC LT lamps (lightbulbs) and chemicals; Etifanos Kebede, Endalew Zemene, and Daneil Emana for supporting laboratory work and sharing their experiences; Girma Gudesho for preparing study maps; Amanuel T/Mariyam for providing GPS instrument; Dr. Desta Ejeta for providing chemicals. Our appreciation is extended to Addis Ababa and Mizan-Tepi Universities for providing financial support and to Jima University for provision of laboratory facilities.

\section{Authors' contributions}

TA: Conceived and designed the experiments; performed the experiments; analyzed and interpreted the data; wrote the paper. DY: Conceived and designed the experiments; contributed reagents and analyzed and interpreted the data; wrote the paper. EG: Contributed reagents and materials, analysis data; wrote the paper. All authors read and approved the final manuscript.

\section{Funding}

This work was financed by Addis Ababa, Jima and Mizan-Tepi Universities. However, these universities had no role in the research design and collection, analysis, interpretation of data and writing of the manuscript.

\section{Availability of data and materials}

All data (generated and analyzed) presented in this study are available from the corresponding author on reasonable request.

\section{Declarations}

Ethics approval and consent to participate

A collection of mosquitoes was carried out after obtaining ethical approval from the ethics review committee of Addis Ababa University (reference no. CNSDO/382/07/15), Amhara Health Regional Bureau (permission reference no. $\mathrm{H} / \mathrm{M} / \mathrm{TS} / 1 / 350 / 07$ ) and the Head of the Bure District Health Office (permission reference no. BH/3/519L/2). Moreover, informed consent was obtained from the selected households.

\section{Consent for publication \\ Not applicable.}

\section{Competing interests}

Addis Ababa, Jima, and Mizan-Tepi Universities financed this research work but had no role in the research design and data collection, conducting of research, and data analysis. Therefore, all authors declare no competing interest.

\section{Author details}

${ }^{1}$ Debre Tabor University, P.O. Box 272, Debre Tabor, Ethiopia. ${ }^{2}$ Jima University, P.O. Box 378, Jima, Ethiopia. ${ }^{3}$ Addis Ababa University, P.O. Box 2003, Addis Ababa, Ethiopia.

Received: 26 November 2020 Accepted: 4 March 2021

Published online: 19 March 2021

\section{References}

1. Koutsos AC, Blass C, Meister S, Schmidt S, MacCallum RM, Soares MB, et al. Life cycle transcriptome of the malaria mosquito Anopheles gambiae and comparison with the fruit-fly Drosophila melanogaster. Natl Acad Sci USA. 2007;23:1-6.

2. Sinka ME. Global distribution of the dominant vector species of malaria. 2013;109- 127

3. Garrett-Jones C, Boreham PF, Pant CP. Feeding habits of anophelines (Diptera: Culicidae) in 1971-1978, with reference to the human blood index: a review. Bull Entomol Res. 1980;70:165-85.

4. Bannister LH, Sherman IW. Plasmodium. In: Encyclopedia of life sciences (ELS). Wiley: Chichester; 2009.

5. The Carter Center. Summary proceedings 4 th annual malaria control program review Ethiopia and Nigeria. Atlanta, Georgia: Carter Center; 2013.

6. Workineh KA, Andualem TM, Gize YA. Assessment of control measures and trends of malaria in Burie-Zuria district, West Gojjam Zone, Amhara Region. North West Ethiopia Malar Res Treatment. 2015;458:1-5.

7. MoH. National Malaria Guidelines. (3rd edt.). Addis Ababa, Ethiopia. Ethiopia Ministry of Health. Addis Ababa, Ethiopia; 2010.

8. Graves PM, Richards FO, Ngondi J, Emerson PM, Shargie EB, Endeshaw $T$, et al. Individual, household and environmental risk factors for malaria infection in Amhara, Oromia and SNNP regions of Ethiopia. Trans R Soc Trop Med Hyg. 2009;103:1211-20.

9. Connor SJ, Dinku T, Wolde-Georgis T, Bekele E, Jima D. A collaborate epidemic early warning and response initiative in Ethiopia;2010.

10. Hay SI. Malaria epidemics in Ethiopia, 2003/2004. Addis Ababa Country Office: Report-II of an individual consultancy to the UNICEF; 2003.

11. Gaffigan TV, Wilkerson RC, Pecor JE, Stoffer JA, Anderson T. Systematic catalog of Culicidae. Walter reed biosystematics unit, division of entomology, Walter reed army institute of research, silver spring; 2013. http:// www.mosquitocatalog.org.

12. MoH. National Malaria Guidelines. (3rd edt.). Addis Ababa, Ethiopia. Ethiopia Ministry of Health. Addis Ababa, Ethiopia; 2012

13. PMI. The President's malaria initiative: eleventh annual report to congress;2017.

14. Gatton ML, Chitnis N, Churcher T, Donnelly MJ, Ghani AC, Gould F, et al. The importance of mosquito behavioral adaptations to malaria control in Africa. Evolution. 2013;67:1218-30.

15. Becker N, Petric D, Zgomba M, Boase C, Madon MB, Dahl C, Kaiser A. Environmental management of mosquitoes: mosquitoes and their control. Berlin Heidelberg: Springer-Verlag; 2010. 
16. Varnado WC, Goddard J, Harrison B. Identification guide to adult mosquitoes in Mississippi. USA: Mississippi State University Extension Service; 2012.

17. Richards SL, Ponnusamy L, Unnasch TR, Hassan HK, Apperson CS. Host feeding patterns of Aedes albopictus (Diptera: Culicidae) in relation to availability of human and domestic animals in suburban landscapes of central North Carolina. J Med Entomol. 2006:43:543-51.

18. Main BJ, Lee Y, Ferguson HM, Kreppel KS, Kihonda A, Govella NJ, et al. The genetic basis of host preference and resting behavior in the major African malaria vector Anopheles arabiensis. PLoS Genet. 2016;12:1-16.

19. Lyimo IN, Ferguson HM. Ecological and evolutionary determinants of host species choice in mosquito vectors. Trends Parasitol. 2009;25:189-94

20. Okwa OO. Malaria, a pending problem in Sub-Saharan Africa, malaria parasites. Nigeria. InTech: Lagos State University (LASU), Lagos; 2012.

21. Molaei G, Andreadis TG, Armstrong PM, Diuk-Wasser M. Host-feeding patterns of potential mosquito vectors in Connecticut, USA: Molecular analysis of blood meals from 23 species of Aedes, Anopheles, Culex, Coquillettidia, Psorophora, and Uranotaenia. J Med Entomol. 2008;45:1143-51.

22. Eckhoff PA. A malaria transmission-directed model of mosquito life cycle and ecology. Malar J. 2011;10:1-17.

23. Garrett-Jones $C$. The human blood index of malaria vectors in relation to epidemiological assessment. Bull World Health Organ. 1964;30:241-61.

24. Kay BH, Boreham PF, Edman JD. Application of the feeding index concept to studies of mosquito host-feeding patterns. Mosq News. 1979;39:68-72.

25. Ree H, Hwang U, Lee I, Kim T. Daily survival and human blood index of Anopheles sinensis, the vector species of malaria in Korea. J Am Mosq Control Assoc. 2001;17:67-72.

26. Mathenge EM, Gimnig JE, Kolczak M, Ombok M, Irungu LW, Hawley WA. Effect of permethrin-impregnated nets on exiting behavior, blood feeding success, and time of feeding of malaria mosquitoes (Diptera: Culicidae) in western Kenya. J Med Entomol. 2001;38:6-531.

27. N'Guessan R, Corbel V, Akogbeto M, Rowland M. Reduced efficacy of insecticide-treated nets and indoor residual spraying for malaria control in pyrethroid resistance area. Benin Emerg Infect Dis. 2007;13:199-206.

28. Kariuki SK, Njunge J, Muia A, Muluvi G, Gatei W, Kuile F, et al. Effect of malaria transmission reduction by insecticide-treated bed nets (ITNs) on the genetic diversity of Plasmodium falciparum merozoite surface protein (MSP-1 and circumsporozoite (CSP) in western Kenya. Malar J. 2013;12:1-8.

29. Bruce-Chwatt LJ, Garrett-Jones C, Weitz B. Ten years study (1955-1964) of host selection by anopheline mosquitoes. Bull World Health Organ. 1966:35:405-39.

30. Garcia-Rejon JE, Blitvich BJ, Farfan-Ale JA, Lorono-Pino MA, Chi- Chim WA, Flores-Flores LF, et al. Host-feeding preference of the mosquito, Culex quinquefasciatus, in Yucatan State. Mexico J Insect Sci. 2010;10:1-5.

31. Gunathilaka N, Denipitiya T, Hapugoda M, Abeyewickreme W, Wickremasinghe R. Determination of the foraging behavior and blood meal source of malaria vector mosquitoes in Trincomalee District of Sri Lanka using a multiplex real time polymerase chain reaction assay. Malar J. 2016;15:1-10.

32. Seyoum A, Balcha F, Balkew M, Ali A, Gebre-Michael T. Impact of cattle keeping on biting rate of anopheline mosquitoes an and malaria transmission around Ziway. Ethiopia East Afr Med J. 2002;79:485-90.

33. I washita H, Dida OG, Sonye OG, Sunahara T, Futami K, Njenga MS. Push by a net, pull by a cow: can zooprophylaxis enhance the impact of insecticide treated bed nets on malaria control? Parasit Vectors. 2014;7:1-13.

34. Boreham PF, Garrett-Jones C. Prevalence of mixed blood meals and double feeding in malaria vector (Anopheles sacharovi Favre). Bull World Health Organ. 1973;48:605-14.

35. Lardeux F, Loayza P, Bouchite B, Chavez T. Host choice and human blood index of Anopheles pseudopunctipennis in a village of the Andean valleys of Bolivia. Malar J. 2007. https://doi.org/10.1186/1475-2875-6-8.

36. Hess $A D$, Hayes $R O$, Tempelis $\mathrm{CH}$. The use of the forage ratio technique in mosquito host preference studies. Mosq News. 1968;28:386-9.

37. Zimmerman RH, Galardo AK, Lounibos LP, Arruda M, Wirtz R. Blood meal hosts of Anopheles species (Diptera: Culicidae) in a malaria-endemic area of the Brazilian Amazon. J Med Entomol. 2006;43:947-56.

38. Dye C, Hasibeder G. Population dynamics of mosquito-borne disease: effects of flies which bite some people more frequently than others. Trans R Soc Trop Med Hyg. 1986;80:69-77.
39. Puente JM, Ruiz S, Soriguer R, Figuerola J. Effect of blood meal digestion and DNA extraction protocol on the success of blood meal source determination in the malaria vector Anopheles atroparvus. Malar J. 2013;12:1-6.

40. Midekisa A, Beyene B, Mihretie A, Bayabil E, Wimberly MC. Seasonal associations of climatic drivers and malaria in the highlands of Ethiopia. Parasit Vectors. 2015;8:1-11.

41. Adugna T, Getu E, Yewhalaw D. Species diversity and distribution of Anopheles mosquitoes in Bure district. Northwestern Ethiopia Heliyon. 2020;6:e05063.

42. Lines JD, Curtis CF, Wilkes TJ, Njunwa KJ. Monitoring human-biting mosquitoes (Diptera: Culicidae) in Tanzania with light-traps hung beside mosquito. Bull Entomol Res. 1991;81:77-84.

43. Mboera LE, Kihonda J, Braks MA, Knols BG. Influence of centers for disease control light trap position, relative to a human-baited bed-net, on catches of Anopheles gambiae and Culex quinquefasciatus in Tanzania. Am J Trop Med Hyg. 1998;59:595-6.

44. WHO. Malaria Entomology and Vector Control: Learner's Guide. In: Trial (Ed.), World Health Organization HIV/AIDS, Tuberculosis and Malaria, Roll Back Malaria. Part l; 2003. https://apps.who.int/iris/bitstream/handle/ 10665/67450/WHO_CDS_CPE_SMT_2002.18_Rev.1_Partl.pdf?seque nce $1 / 41$

45. WHO. WHO Manual on Practical Entomology in Malaria, Part-II. From. WHO, Geneva; 1975. From: https://apps.who.int/iris/bitstream/handle/ 10665/42481/WHO_OFFSET_13_\% 28part1\%29.pdf?sequence1/41.

46. Verrone GA. Outline for the determination of malaria mosquitoes in Ethiopia: Part-I-Adult female Anopheles. Mosq News. 1962;22:37-50.

47. Gillies MT, Coetzee M. A supplement to the Anophelinae of Africa south of the Sahara (Afrotropical region). Johannesburg South Afr Insect Med Res. 1987:55:1-125.

48. Wilkins EE, Howell PI, Benedict MQ. IMP PCR primers detect single nucleotide polymorphisms for Anopheles gambiae species identification, Mopti and Sahavanna rDNA types, and resistance to dieldrin in Anopheles arabiensis. Malar J. 2006:5:1-7.

49. DNeasy Blood and Tissue Kits. DNeasy Blood and Tissue Handbook; 2011. www.qiagen.com.handbooks.

50. WHO. Malaria entomology and vector control: Guide for participants; 2013.

51. Beier JC, Perkins PV, Wirtz RA, Koros J, Diggs D, Gargan TP, Koech D. Blood meal identification by direct enzyme-linked immunosorbent assay (ELISA) tested on Anopheles (Diptera: Culicidae) in Kenya. J Med Entomol. 1988;25:9-16

52. Tirados I, Costntni C, Gibson G, Torr SJ. Blood-feeding behaviour of the malarial mosquito Anopheles arabiensis: implications for vector control. Med Vet Entomol. 2006;20:425-37.

53. Mala AO, Irungu LW, Shililu JI, Muturi EJ, Mbogo CM, Njagi JK, Mukabana WR, Githure Jl. Plasmodium falciparum transmission and aridity: a Kenya experience from the dry lands of Baringo and its implications for Anopheles arabiensis control. Malar J. 2011;10:1-9.

54. Massebo F, Balkew M, Gebre-Michael T, Lindtjorn B. Entomological inoculation rates of Anopheles arabiensis in southwestern Ethiopia. Am J Trop Med Hyg. 2013;89:466-73.

55. Mayagaya VS, Nkwengulila G, Lyimo IN, Kihonda J, Mtambala H, Ngonyani $\mathrm{H}_{\text {, et }}$ al. The impact of livestock on the abundance, resting behaviour $\&$ sporozoite rate of malaria vectors in southern Tanzania. Malar J. 2015:14:1-10.

56. Getachew D, Gebre-Michael T, Balkew M, Tekie H. Species composition, blood meal hosts and Plasmodium infection rates of Anopheles mosquitoes in Ghibe River Basin, southwestern Ethiopia. Parasit Vectors. 2019;12:257.

57. Fornadel C, Norris LC, Glass GE, Norris DE. Analysis of Anopheles arabiensis blood feeding behavior in southern Zambia during the two years after introduction of insecticide-treated bed-nets. Am J Trop Med Hyg. 2010;83:848-53.

58. Bashar K, Tuno N, Ahmed TU, Howlader AJ. Blood-feeding patterns of Anopheles mosquitoes in a malaria-endemic area of Bangladesh. Parasit Vectors. 2012:5:51-10

59. Costantini C, Sagnon N, Sanogo E, Merzagora L, Coluzzi M. Relationship to human-biting collections and influence of light and bed-net in CDC light-trap catches of West African malaria vectors. Bull Entomol Res. 1998;88:503-11. 
60. Animut A, Balkew M, Gebre-Michael T, Lindtjorn B. Blood meal sources and entomological inoculation rates of Anophelines along a highland altitudinal transect in south-central Ethiopia. Malar J. 2013;12:112-21.

61. Norris LC, Fornadel CM, Hung W, Pineda FG, Norris DE. Frequency of multiple blood meals taken in a single gonotrophic cycle by Anopheles arabiensis mosquitoes in Macha. Zambia Am J Trop Med Hyg. 2010;83:33-7.

62. Massebo F, Balkew M, Gebre-Michael T, Lindtjorn B. Blood meal origins and insecticide susceptibility of Anopheles arabiensis from Chano in south-west Ethiopia. Parasit Vectors. 2013:6:1-10.

63. Yewhalaw D, Kelel M, Getu E, Temam S, Wessel G. Blood meal sources and sporozoite rates of Anophelines in Gilgel-Gibe dam area, Southwestern Ethiopia. African J Vectors. 2014; https://www.researchgate.net/publi cation/292615632_Blood_meal_sources_and_sporozoite rates of Anophelines_in_Gilgel-Gibe_dam_area_Southwestern_Ethiopia.

64. Ngom NE, Ndione J, Ba Y, Konate L, Faye O, Diallo M, Dia I. Spatiotemporal analysis of host preferences and feeding patterns of malaria vectors in the sylvo-pastoral area of Senegal: impact of landscape classes. Parasit Vectors. 2013;6:1-10.

65. Hadis M, Lulu M, Makonnen Y, Asfaw T. Host choice by indoor resting Anopheles arabiensis in Ethiopia. Trans R Soc Trop Med Hyg. 1997:91:376-8.

66. Bogh C, Clarke SE, Pinder M, Sanyang F, Lindsay SW. Effect of passive zooprophylaxis on malaria transmission in the Gambia. J Med Entomol. 2001;38:822-8.

67. Kiszewski A, Mellinger A, Spielman A, Malaney P, Sachs SE, Sachs JA. Global index representing the stability of malaria transmission. Am J Trop Med Hyg. 2004;70:486-98.

68. Muriu SM, Muturi EJ, Shililu JI, Mbogo CM, Mwangangi JM, Jacob BG, et al. Host choice and multiple blood feeding behaviour of malaria vectors and other anophelines in Mwea rice scheme. Kenya Malar J. 2008;7:1-7.

69. Lyimo IN, Nghabi KR, Mpingwa MW, Daraja AA, Mwasheshe DD, Nchimbi NS, et al. Does cattle milieu provides a potential point to target wild exophilic Anopheles arabiensis (Diptera: Culicidae) with entomopathogenic fungus? A bioinsecticide zooprophylaxis strategy for vector control. J Parasitol Res. 2012:222:1-9.

70. Habtewold T, Walker AR, Curtis CF, Osir EO, Thapa N. The feeding behaviour and Plasmodium infection of Anopheles mosquitoes in southern Ethiopia in relation to use of insecticide-treated livestock for malaria control. Trans R Soc Trop Med Hyg. 2001;95:584-6.
71. Mwangangi JM, Mbogo MC, Nzovu JG, Githure JI, Yan Y, Beier JC. Blood meal analysis for anopheline mosquitoes sampled along the Kenyan coast. J Am Mosq Control Assoc. 2003;19:371-5.

72. Tanga MC, Ngundu WI, Tchouassi PD. Daily survival and human blood index of major malaria vectors associated with oil palm cultivation in Cameroon and their role in malaria transmission. Trop Med Int Health. 2011;16:447-57.

73. Pates $\mathrm{H}$, Curtis C. Mosquito behavior and vector control. Annu Rev Entomol. 2005:50:53-70.

74. Kibret S, Wilson GG, Ryder D, Tekie H, Petros B. Malaria impact of large dams at different eco-epidemiological settings in Ethiopia. Trop Med Health. 2017:45:1-14

75. Kelel M. Anopheles mosquitoes host preference and malaria transmission intensity using immunological diagnostic methods in Gilgel-gibe dam area, southwestern Ethiopia. Addis Ababa University. [MSc. Thesis]. 2010 p. 37-41.

76. Adugna T, Yewhelew D, Getu E. Species diversity and entomological inoculation rate of anophelines mosquitoes in an epidemic prone areas of Bure district, Northwestern Ethiopia Malar J. 2020. https://doi.org/10. 21203/rs.3.rs-103609/v1.

77. Antonio-Nkondjio C, Kerah CH, Simard F, Awono-Ambene P, Chouaibou $M$, Tchuinka T, Fontenille D. Complexity of the malaria vectorial system in Cameroon: contribution of secondary vectors to malaria transmission. J Med Entomol. 2006:43:1215-21.

78. Gegefa T, Zeynudin A, Godesso A, Haile-Michael Y, Eba K, Zemene E, et al. Malaria incidence and assessment of entomological indices among resettled communities in Ethiopia: a longitudinal study. Malar J. 2015;14:1-10.

79. Ogola E, Villinger J, Mabuka D, Omondi D, Orindi B, Mutunga J, et al. Composition of Anopheles mosquitoes, their blood-meal hosts, \& Plasmodium falciparum infection rates in three islands with disparate bed net coverage in Lake Victoria. Kenya Malar J. 2017;16:1-11.

80. Burkot TR, Graves PM, Paru R, Lagog M. Mixed blood feeding by the malaria vectors in the Anopheles punctulatus complex (Diptera: Culicidae). J Me Entomol. 1988;25:205-13.

\section{Publisher's Note}

Springer Nature remains neutral with regard to jurisdictional claims in published maps and institutional affiliations.
Ready to submit your research? Choose BMC and benefit from:

- fast, convenient online submission

- thorough peer review by experienced researchers in your field

- rapid publication on acceptance

- support for research data, including large and complex data types

- gold Open Access which fosters wider collaboration and increased citations

- maximum visibility for your research: over $100 \mathrm{M}$ website views per year

At BMC, research is always in progress.

Learn more biomedcentral.com/submissions 